\title{
Artist and Repertoire Goes Online: Evidence from Poland
}

\author{
Patryk Galuszka and \\ Katarzyna M. Wyrzykowska'
}

\author{
University of Lodz and Polish Academy of Sciences \\ patrykgaluszka@gmail.com and katarzyna @ wyrzykowska.net
}

\begin{abstract}
:
This article uses the concept of social network markets to analyze the problem of uncertainty in the music industry. On the basis of empirical data, the article puts forward the argument that to understand the preferences of listeners, a music company must be embedded in social networks. This embeddedness has always been an asset, as is indicated by the successes of independent record companies. However, nowadays it has become easier due to the ever-widening spread of social networking sites. We demonstrate that a company that communicates with its consumers via a Facebook profile or a YouTube channel on a regular basis gains the opportunity to analyze this communication, which, along with other data obtained via the internet, can help in reaching music repertoire decisions. At the same time, these practices may lead to the infringement of recipients' privacy and the commodification of all actions undertaken by listeners online.
\end{abstract}

Keywords: Networks, Marketing, Big Data, Recording Industry, Surveillance

It has been widely accepted that one of the distinguishing features of creative industries is their inability to foresee which products will become popular. Uncertainty is an inherent feature of every business activity, but in the case of cultural production, the problem is deeper. It is associated with the difficulties surrounding market research. On one hand, these difficulties arise out of the inadequacy of traditional research methods in the study of cultural products. On the other hand, these difficulties are inherent in the specific features of these products, that is, compared with other industries, in terms of product testing, a producer needs to invest a disproportionately large sum of money relative to the percentage of costs of the final release. ${ }^{2}$ Richard Caves describes these phenomena as such: "[ $\left.\mathrm{t}\right]$ he producer's intimate knowledge of the good's production process still leaves him in the dark about whether consumers will like it: nobody knows"33 (emphasis in original).

The increasing availability of "big data" raises the question of whether the "nobody knows" principle can be overcome by the creative industries. One might question whether the availability of more data will automatically translate to a higher success ratio for the creative industries. Nonetheless, we believe that more research is necessary to understand how cultural producers make use of the information gathered on the internet. It can be assumed that 
various cultural producers have different opinions about and attitudes toward information gathered on the internet-information that should be reflected in their market performance. In other words, the fact that "nobody knows" does not mean that all cultural producers react to this lack of knowledge in the same way.

This paper uses empirical data gathered from record labels operating in Poland to address how cultural producers formulate their knowledge about listener preferences in the internet age. The aim of our paper is to research the methods of market analysis used by record labels on the eve of the common availability of "big data" and to attempt to identify the causes of possible differences in the research practices of particular record labels. The Polish market meets the criteria for our study because, although the internet is widely used for promoting music, digital music sales constitute only about 26 percent of recorded music revenues. ${ }^{4}$ This market is also characterized by the strong position of hip-hop music, which is released entirely by a group of independent record labels. To investigate the success of Polish hip-hop record labels specifically, we use the concept of the music market as a social network market. ${ }^{5}$

The paper consists of eight sections. The "Artists and Repertoire and the Nature of the Music Commodity" section discusses traditional methods of conducting market research in the recording industry. "The Music Market as a Social Network Market" section presents the concept of "social network markets" proposed by Potts et al. ${ }^{6}$ The "Commoditization of Market Information" section considers problems resulting from the commoditization of market information. The "Methodological Note" section presents the method for the collection of empirical data. In the "Three Approaches to Conducting Market Research" and "Toward Virtual A\&R" sections, we present the empirical data demonstrating how record companies make use of new sources of information about the preferences of record buyers. The last section summarizes the analysis and points to potential new directions for the development of music market research methods.

\section{Artists and Repertoire and the Nature of the Music Commodity}

Cultural theorists point to the fact that the recording industry does not respond to preexisting demand. Instead it leads to "certain social groups selected as commercial targets to prepare themselves to respond to the producers' offer." ${ }^{7}$ Even if consumers buy the recording, they rarely buy more than one copy of it. This means that a given release has "a finite upper limit on sales ... equal to the number of potential purchasers." ${ }^{8}$ These two factors, combined with the impossibility of pretesting music products, result in overproduction. Releasing various new titles in the hope that one of them will become a hit is a logical response by those producers who can afford signing contracts with several artists. Consequently, the market for music is not only unpredictable but also extremely competitive: only a small percentage of released recordings turn a profit. In the case of big record companies, this is said to be approximately 10 to 15 percent of released albums. ${ }^{9}$ This model has consequences for the repertoire of an average record company, as the company must generate a hit from time to time to cover the costs of unsuccessful titles and survive as a business. Being unable to predict which song or album will become a hit leads to record labels constructing "portfolios of projects" consisting of various acts (emphasis in original). ${ }^{10}$ 
Operating in such a risky environment, the recording industry had to work out its own methods for analyzing artists' potential. These are based on the assessments of Artists and Repertoire (A\&R) experts. As Simon Frith puts it,

Though in the short term a record company's success may reflect the effectiveness of its salesmenpluggers, press office, distributors, sales reps - in the long run success depends on A\&R judgments who to sign, how to record and present them to the public. ${ }^{11}$

A\&R experts are somewhat able to reduce uncertainty about the market potential of a given artist by observing the artist on stage, by monitoring their interaction with the audience, and by evaluating their previous recordings (if they made any). Empirical studies conducted in the Netherlands show that local A\&R managers "mentioned the importance of the live performance, quality of the music, musical skills, appearance, motivation as well as potential media and audience appeal."12 As a majority of these factors are highly subjective, A\&R managers try to maintain a distance from the evaluated artists by focusing on "the selling potential of artists." ${ }^{13}$ In practice, this may involve, for example, determining whether radio stations would broadcast the artist's recordings. If the answer is negative in spite of a subjectively high evaluation of the quality of the artist's music, the A\&R manager should conclude that the artist's chances for mass popularity are limited.

It is important to ask how record labels use, or plan to use, new communication technologies to decrease the uncertainty surrounding the success or failure of released products. The idea suggesting that communication technologies can be applied to market analysis has been around for some time now since early 2000s. Keith Negus wrote about the changes taking place in the digital music market, noting that,

A\&R staff are actively using more market intelligence, market research and web analytics (monitoring plays on different platforms, using BuzzDeck, monitoring YouTube activity, SoundCloud plays) tracking social media (MySpace, Facebook friends and Twitter followers), along with other data gathering techniques (focus groups, questionnaires) and accounting knowledge (highly detailed analysis and profiles of individual artists and their revenue streams). ${ }^{14}$

Jeremy Morris builds on this analysis. Morris chronicles the development of "infomediaries organizational entities that monitor, collect, process, and repackage cultural and technical usage data into an informational infrastructure that shapes the presentation and representation of cultural goods." ${ }^{15}$ These entities collect data about listeners' online activities, for example, in streaming services, social networks, blogs, and so forth. After these data have been analyzed, they can be used by streaming services or by record labels that can afford access to these analyses. Although the development of "music intelligence" companies constitutes a new dimension ${ }^{16}$ to the music industry, ${ }^{17}$ it is mostly major record companies and record labels from the largest markets that have access to this type of service. Our article, however, focuses on a market (Poland), where at present the majority of record labels have no access to infomediary services, are not aware of their existence, or are not interested in them.

\section{The Music Market as a Social Network Market}

As noted above, the issue of uncertainty is a key element of analysis conducted by Potts et al., who consider it to be a factor that differentiates creative industries from other 
industries. ${ }^{18}$ They argue that, as far as creative products are concerned, "because of inherent novelty and uncertainty, decisions both to produce and to consume are determined by the choice of others in a social network." ${ }^{19}$ As the problem of uncertainty is central to the concept of social network markets, we found this framework suitable for our analysis. It should be noted that this concept was born within the field of economic sciences and therefore emphasizes different aspects of human behavior than its sociological counterparts, which focus on concepts such as field, art worlds, and scenes. Contrary to these concepts, the idea of social network markets concentrates on explaining the coevolutionary process in which certain cultural products or phenomena become popular and others do not.

Although relationships between artists and audiences online have been studied thoroughly, ${ }^{20}$ the concept of social network markets brings a distinct perspective due to its concentration on economic processes, such as the increasing market value of a song thanks to the complex interactions of listeners sharing information about that song. However, this concept also differs from mainstream neoclassical economics, as the social network markets perspective assumes that the price signals in social network markets are secondary to the signals shared between the participants of a social network. This is the case, for example, due to choices observed and interpreted by other participants in the network. ${ }^{21}$ In social network markets, the price is of relatively little importance to the consumer: while it is a significant factor that may prevent him or her from buying a recording ("I'm not going to buy it because I can't afford it"), it has little effect on the consumer's choice of which recording to buy. This is due to the fact that an average buyer of recordings will likely not be interested in buying a recording by an unfamiliar artist only because it is being sold at a discounted price. However, the consumer may consider buying it if he or she remembers that several persons with trustworthy tastes (members of the same musical social network) evaluated it highly. A new recording, or a recording by an artist unfamiliar to the consumer, is an example of products "over which consumers do not have well established decision rules for choice." 22 In turn, from the viewpoint of a record label, these recordings constitute products about which "producers do not have deep knowledge or power regarding what products will be of value and so must experiment to discover these." 23

It should be emphasized that social network is a much broader concept than social networking sites. Analysis of social networks "is built on the idea that there is a determinable structure to how people know each other, whether directly or indirectly," ${ }^{24}$ whereas social networking sites are only an online reflection of the existence of mutual connections. In other words, connections have always existed, whereas internet-based sites that facilitate the building and maintaining of social networks are relatively new phenomena.

According to Potts et al., the value of creative products, which is extremely difficult to evaluate in the beginning (i.e., when they are created), is "socially determined by complex networks of individual interactions." ${ }^{25}$ This observation is consistent with the opinion expressed by sociologists and social psychologists that musical preferences are shaped socially. ${ }^{26}$ From the viewpoint of a record label, the issue here is the transition from the awareness of the social mechanism of shaping musical preferences to ongoing decisions concerning the company's offerings. In the case of music, social networks have always existed, for example, in the form of fan communities. ${ }^{27}$ What record companies' A\&R experts did before recommending that a record company sign a new artist was to a large extent based on the 
observation of social networks, for example, watching listeners' interactions with artists and with each other during concerts. Following this line of reasoning, it can be argued that independent record companies were considered to be better than major companies in discovering new talents ${ }^{28}$ not because of their ability to foresee the future but because of their embeddedness in music scenes - scenes that were composed of social networks of fans, artists, journalists, club owners, and so forth.

Today, with the advent of new communication technologies, social networks are easier to observe than they were twenty or thirty years ago. ${ }^{29}$ Due, in particular, to the rise of social networking sites, a great deal of information is available to both record companies and researchers. Obviously, interpreting information gathered in this way may be not as easy as it seems, yet it seems difficult to ignore that (especially in the case of some music genres) record companies, artists, and listeners have greater opportunities for interactions that can be registered and analyzed. It is highly probable that we are experiencing only a foreshadowing of the analytical tools that are becoming available following the advent of "big data" (e.g., subscription services that can monitor consumers' listening behavior in real time). ${ }^{30}$ This is not to say that the music industry is on the eve of the end of uncertainty, but rather to suggest that new communication technologies can deliver information that, if properly analyzed, could be crucial in adapting market behavior or even the organization of record companies. At the same time, however, the search for progressively more sophisticated methods of gathering data on listeners means limiting the listeners' privacy, thereby increasing the likelihood of exploitation.

\section{Commoditization of Market Information}

While analyzing the development of new methods of market research, it is impossible not to notice that, in many cases, these methods constitute a radical change in approach to the issue of listeners' privacy. The transition from a recording industry based on physical products (such as CDs) to circulating intangible digital products (such as files or streaming) creates the possibility of registering, monitoring, and analyzing the behaviors of buyers fairly easily. The adoption of the customer-relationship management concept by the biggest entities on the music market (e.g., digital music stores) is a manifestation of companies taking advantage of this possibility. Thanks to gathering and analyzing data concerning consumers, the customer-relationship management concept allows for the preparation of a personalized offer (i.e., offers tailored to the expectations of a given listener). ${ }^{31}$ This still does not solve the issue of lack of knowledge, which content creators, that is, record labels, are battling against. Nevertheless, it makes it easier for music retailers, such as iTunes and Spotify, to function. From the perspective of users (i.e., listeners, recipients, and fans), it is a practice that may be used to infringe on their privacy; a traditional record store in the days before the popularization of the Internet had no easy means of collecting and processing data on its clients.

However, the limitation of privacy is not the biggest problem connected to the increasingly intense surveillance of listeners' behaviors. Mark Andrejevic, referring mainly to television, argues that while receiving media content, the audience performs "the work of being watched" $^{32}$ (emphasis given in the original), which, in a symbolic way, reflects the fact that the producers and providers of content are not only interested in the demographic profile of 
recipients, but also in knowing their every behavior related to the reception of content. His analysis also may be applied to the music industry, because the mechanism of monitoring the behaviors, for example, of users of subscription services, is the same as in the case of television viewers. Knowledge about what these behaviors entail, in relation to both a particular user and the entire market, has economic value. As a result, data and any data analysis service that may accompany the data become a product. Such knowledge translates into notable profits for companies, thanks to products being better tailored to the needs of narrower and narrower market segments. Andrejevic writes that "the promise of interactive communication technologies is to surpass the structural limitations that prevented the exploitation of increasingly compact market niches." ${ }^{33}$ Access to data and the ability to analyze the data give companies a competitive advantage, of course, if we assume that "the systematic use of personal information to predict and influence behavior" ${ }^{34}$ is worth the cost of gathering such information. In the case of the music market, data are gathered and analyzed by the aforementioned infomediaries; however, their services may prove to be too expensive for some independent record labels.

It may be too early to worry that unequal access to such data will increase the strength of major record labels; nevertheless, the advantages that such access offers should not be underestimated. The following quote proves that the information gathered by infomediaries is not merely a negligible data set about the favorite songs of a particular user:

Pandora said it had begun selling political ads based on the listening patterns of its 75 million users - Bob Marley fans are usually Democrats, for example, while gospel and country listeners lean Republican. ${ }^{35}$

One more issue should be mentioned here. It is not clear what kinds of data the subscription services share with record labels. It can be assumed that major record companies, which have a bargaining advantage over subscription services (i.e., they control the valuable asset: music catalogs), and in some cases also have ownership stakes in these services (e.g., in Spotify $\left.{ }^{36}\right)$, can access the most attractive data. Smaller labels may have no access to data gathered by subscription services. Although smaller labels still can buy significant amounts of data from infomediaries, they are clearly disadvantaged by having to pay for something that others (majors) get for free.

\section{Methodological Note}

The rest of this article is focused on a study of the Polish recording market that was conducted in 2013 at the request of the Institute of Music and Dance, Polish Music Information Centre, and Ministry of Culture and National Heritage of the Republic of Poland. As part of the project, fifty semistructured in-depth interviews were conducted with representatives of record companies (see the appendix). Concrete cases for the investigation were chosen on the basis of two criteria: differentiation according to music specialization and differentiation according to the size of the company. This approach made it possible for the study to examine diverse subjects, thereby keeping with the character and dynamics of the Polish recording industry.

Of the fifty-three respondents, the vast majority were male (only five women took part in the study as they were underrepresented in the studied companies). The interviewees held the following posts: owner, chairman, director (executive, managing, program, etc.), head of 
department, and manager. This diversity of respondents was, to a large degree, the result of the different organizational structures and sizes of the respective companies. In spite of this variability, what united the interviewees was their comprehensive knowledge of the workings of the companies they represented. Taking into consideration their professional experience in the record industry, the sizeable group consisted of people with more than ten years of experience (although relative beginners with two to three years of work experience were included in the study in isolated cases).

In 2014, recorded music revenue in Poland totaled $\$ 79$ million, which gave the Polish market the 22nd position globally; 71 percent of sales were physical and 18 percent were digital. ${ }^{37}$ Data for the first half of 2016 show an increase in the popularity of digital formats, which constituted 28.91 percent of all recording sales. ${ }^{38}$ It is worth emphasizing that the contribution of digital recordings to the Polish music industry has been increasing gradually since the largest streaming services entered the Polish market in 2012 (Deezer) and in 2013 (Spotify). In addition, even though the CD is still the most popular music format in Poland, for some time now, a significant number of companies have been using the internet as their basic marketing communications channel and the place where they sell their tangible records. During the last few years, there has also been a steady increase in the sales of vinyl records.

Although exact numbers are difficult to obtain, the interviews conducted with respondents suggest that the structure of the Polish recording market is similar to other European markets. Three major record labels control about 60 to 70 percent of the market, whereas the rest of the market is divided among approximately 200 small- and medium-sized record labels. Recordings by Polish artists enjoy significant popularity $(40.23 \%$ share of all sales in the first half of 2016), whereas non-Polish recordings amounted to 41.59 percent. (The rest of the market was split between compilations at $13.6 \%$, and classical music at $4.59 \% .{ }^{39}$ )

\section{Three Approaches to Conducting Market Research}

Using the collected empirical material, we identified three different approaches to conducting market research. The first approach, characteristic of major record companies and medium-sized independent companies, involves applying the marketing practices known from other industries to the music market. This includes the segmentation of the market, attempts to obtain information about a given market segment (through classic A\&R actions and through broader uses of big data), and by tailoring the offerings of a given record label to the needs of selected, researched segments.

Major record companies are the only entities to undertake initial research on consumers' preferences (e.g., questionnaires or focus group interviews) - a practice that is standard in other industries. Notably, this research is seldom used, as it is not seen as yielding credible results. Smaller labels do not commission such research both because of its low credibility and its high cost. The following statement illustrates the inadequacy of this traditional market research:

We introduced these studies, we did them, and some absurd things came up that had no relation to the market. I don't know if they were badly, badly done, these studies . . . Maybe people got the names of the bands mixed up ... I remember that some, some complete nonsense was coming out. 
Instead of relying on traditional market research methods, smaller labels base their decisions on conclusions coming from some form of A\&R activity. It should be noted, however, that the vast majority of the labels examined in the study did not have a separate A\&R department. Only major record companies have such a specialized department; mediumand small-sized labels are too small to employ a person whose sole task is to find new artists. As a result, when labels declare that they are making decisions based on A\&R activity, these tasks are usually divided equally between different employees or are taken up by the owner:

We don't have a separate department like that. When I want to find some new artists, I go to concerts. We don't really need to find new artists anyway, because they send us demos themselves. And then there are TV shows.

In general, labels representing this approach analyze the market using methods well described in the subject literature. ${ }^{40}$ Although most of them did not show particular interest in engaging in analysis of data coming from the internet when our interviews were conducted, it can be assumed that the situation has changed due to the subsequent popularization of music streaming in Poland.

The second approach is characteristic of medium- and small-sized record labels with a strong position in their niche. This approach involves, first and foremost, drawing benefits from a given label's strong position in social media. Thanks to this position, a record label knows a considerable amount about its audience and the artists operating in a given niche. This knowledge also comes from commonly accessible and free sources of information, such as YouTube or Facebook, but it does not entail using the paid services of infomediaries. Practically all the labels representing this approach release hip-hop music. In comparison with other labels, these labels are quite innovative in terms of using the internet for market research. As such, they are subject to more detailed analysis in the next section.

The third approach involves an ostentatious rejection of any "market research," seeing such practices as corrupting art. It is worth noting here that such record labels (representing various music genres other than hip hop) reject gathering and analyzing data not because of their beliefs regarding the harmfulness of surveilling users, but rather because of their critical approach (or at least, their declared critical approach) to yielding to the market. Of course, we can indicate certain contradictions here, because such companies, provided that they do not operate on a nonprofit basis, have to consider the sales volume of each title sold to at least some extent. They likely attribute all of the differences in the sales of their releases primarily to whether the listeners have recognized the "quality" of their music.

Despite frowning on market research, record labels representing this approach do not release music only based on aesthetic criteria. Rather, they often decide what to release based on peer recommendation networks, relying on proven contacts, and their intuition and knowledge of a given musical scene:

You know, ... these are contacts built over many years. We know a lot of people in the field from the whole country. So it's all a matter of contacts. No one is going to put out an ad that they're looking for a band or a vocalist. It's all done through contacts with people who know who to find and where. 
A study by Zwaan and ter Bogt also emphasized the importance of professional networks in A\&R activity. ${ }^{41}$ This corresponds with the statement that the music market is a "social network market." Just as listeners shape their opinions of artists based on the recommendations of their social networks, the employees of record companies take advantage of their own networks. In the case of the Polish market, especially in genre niches, the relatively small size of certain musical scenes may be important. Monitoring such a scene is possible without expending excessive sums on A\&R activity. Instead, "being up-to-date" and having the support of a social network is enough:

When it comes to working with acts, I think we have a basic, or even more than basic, understanding of what's happening in the market. These are, in the case of, let's call it debuts, opinions, or suggestions from people we have worked with before, people we trust. Or sometimes we just go to a concert, we listen, and we find a wow.

In some cases, labels belonging to this group ostentatiously criticize not only conducting research online but also the general direction in which the internet has been evolving:

I do not use social networking sites because I am conservative and I think that it does not bring any results. For me, such websites are just tools for collecting personal information and use them without the user's permission. Everything on the internet is an illusion, and it is lacking deeper meaning.

\section{Toward Virtual A\&R}

As noted above, the second approach, involving exploiting social media services, is characteristic of Polish hip-hop labels. These labels are increasingly using data from the internet to aid in their repertoire decision making. It is worth emphasizing, however, that they do not use information provided by external research companies; they are satisfied with the interpretation of data which is available free of charge. In the opinion of one of the respondents, such data complement what the company already knows thanks to close contact with its customers, which is typical for hip-hop record labels in Poland:

Preferably we monitor [the market] on a regular basis with the aid of the internet, with widely available tools. ... That is, Google Access provides us with a lot of information, also statistics on YouTube and Facebook. That's enough. There is no point in spending money on it; at this time, when we have such a direct contact with our target group, a simple question which we put on Facebook instantaneously gives us several hundred replies . . . black on white, yes. Well, I don't have to pay for this. It's fantastic, it's the 21st century.

This statement corresponds to the idea that the music market has a social network market character. According to Potts et al., "social ... means the ability of one agent to connect to and interpret information generated by other agents, and to communicate in turn." ${ }^{42}$ In the example above, such an agent-for example, the company -is able to enter into a dialogue with other agents - its consumers - via social networking sites. Monitoring the reactions of listeners who participate in this dialogue provides the record company with information about the market that far exceeds what a singular employee of an A\&R department could provide. Nevertheless, at the same time, a representative of this record label that we spoke with is convinced that it is not worth spending money on purchasing reports from external research companies. No study has been conducted to verify if this perspective is due to a perception of the uselessness of such data, or rather from the lack of attractive offers from such 
companies. It is most likely that when our research was being conducted, companies such as the Echo Nest ${ }^{43}$ did not possess data that Polish record labels would find attractive.

A respondent representing a different hip-hop record company stated that they made use of three basic sources of information from which they based their forecasts for the market potential of recordings: social media, analysis of activity in their internet store, and statistics provided by the distributors of both physical and digital media. YouTube occupies a special position for them and enables the record company to see where potential consumers for their products live. The lack of access to certain music videos in Germany (caused by the absence of an agreement between Google and GEMA ${ }^{44}$ ) results in their inability to analyze that market using YouTube.

The following statement points to the possibility for a comprehensive application of new media to evaluate the market potential of an emerging artist:

Now, because there are these social media ... we can always check how many fans he has, how big is the interaction between him and these fans; there is also an internet forum which is some indicator for us ... dedicated to rap music alone ... we can also assess what are the dominating sentiments ... surrounding the artist.

The above statement shows that, in the case of this record company, market analysis extends beyond the evaluation of data passed on by the distributors or collected on YouTube. In this case, a more appropriate term for the evaluation of the interaction between the artist and his listeners would be "virtual A\&R." Obviously, it is difficult even for an in-depth analysis of an internet forum to replace a visit by a record company employee to an artist's concert. It can, however, be a wonderful supplement to such a visit.

How can we critically evaluate the practices used by record labels specializing in hip-hop music? The range of data gathered by these record labels is considerably smaller than the data collected by infomediaries. What is important is that these smaller labels obtained the data on their own or they accessed "commonly available information" (e.g., looked at the number of views for a video on YouTube). Importantly, the data are not the subject of a transaction. Thus, we are dealing with the scope of traditional A\&R actions being expanded with the internet, rather than representing the first step toward Andrejevic's "digital enclosures," which aims at separating users from the means of interaction. ${ }^{45}$ However, it should be noted that the overlap between the Polish hip hop labels and digital enclosures is fluid and that the research methods used by the former may represent the first step toward a more systematic surveillance of listeners.

It is difficult to assume that record labels representing other types of music will consistently avoid using similar methods of market analysis. We can rather expect that observing the effectiveness of these methods as used by hip-hop companies will bring about the application of similar methods by record labels specializing in other types of music. A question arises, however, as to why exactly it is that hip-hop record labels are pioneers in these new methods of market analysis.

Using the social network markets concept, we would like to suggest that one of the possible reasons for the success of Polish hip-hop record labels in market analysis is due to the position that they have in the new media ecosystem. It is easiest to illustrate this by referring to the data contained in Table 1. The hip-hop labels' numbers exceed the biggest (in terms of market share) record company in Poland (the Polish branch of Universal Music) by far. They 
also exceed two randomly chosen independent record labels that are an important part of the Polish market but that do not release hip-hop music. These data certainly do not reflect the actual market position of these companies; the lower activity of the non-hip-hop record labels is compensated for by their presence in, for example, TV, radio, and the press. The data, however, do show exactly what the respondents of this study have pointed out: the hip-hop record labels can learn from monitoring social media more than other labels because for hip-hop audiences, these media are preferred means of communication (unlike, for example, classical music listeners). What is more, the specificity of communication in social media fits into ways of building relationships with fans characteristic of hip-hop culture almost from the very beginning ${ }^{46}$ (i.e., focusing on direct contact, shortening distances, etc.). One of the respondents described this as follows:

Digital media forces you to learn all over again how to communicate with your audience. However, in hip-hop culture the distance between the artist and real life was always quite small. In the US, an example of such direct forms of communication can be Method Man or Redman. Snoop Dog is a pop cultural icon (. . .) In Poland hip-hop artists are constantly learning how cool and useful Facebook is, and how daily posts with some interesting things and events can keep people engaged. And our fans can feel honored that they are in constant contact with their idols.

Given this context, it is not surprising, therefore, that hip-hop labels use social media on such a broad scale. Moreover, we could also assume that because hip-hop music is more popular in Poland than, for example, punk rock, hip-hop labels are better positioned on Facebook and YouTube. To a large degree, this is true; however, the strong position of the hip-hop record labels is also the result of many years of building a consumer community. Applying the concepts discussed earlier in this paper, we can argue that hip-hop record companies in Poland have become an important element of the social network market for consumers of this type of music; they both respond to the needs of the consumers and act as

Table 1. A Comparison of the Presence of Different Record Companies in New Media.

\begin{tabular}{|c|c|c|c|c|c|}
\hline \multirow[t]{2}{*}{ Record company } & \multirow[t]{2}{*}{ Music genre } & \multicolumn{2}{|c|}{ No. of Facebook likes } & \multicolumn{2}{|c|}{$\begin{array}{l}\text { No. of YouTube } \\
\text { subscribers }\end{array}$} \\
\hline & & $\begin{array}{c}\text { As of } \\
\text { December 14, } \\
2015\end{array}$ & $\begin{array}{c}\text { As of } \\
\text { January 5, } \\
2017\end{array}$ & 2015 & 2017 \\
\hline Prosto & Hip-hop & 320,728 & 334,131 & $1,119,036$ & $1,302,770$ \\
\hline Step Records & Hip-hop & 155,773 & 178,078 & $1,323,819$ & $1,875,382$ \\
\hline Wielkie Jol & Hip-hop & 126,701 & 127,749 & 21,966 & 23,775 \\
\hline Szpadyzor & Hip-hop & 51,696 & 50,420 & 99,948 & 105,906 \\
\hline Asfalf Records & Hip-hop & 46,435 & 53,542 & 259,509 & 337,632 \\
\hline Universal Music Polska & $\begin{array}{l}\text { Various (major record } \\
\text { company) }\end{array}$ & 43,130 & 55,792 & 24,525 & 28,668 \\
\hline Kayax & $\begin{array}{l}\text { Various } \\
\text { (independent } \\
\text { record label) }\end{array}$ & 9,675 & 12,062 & 9,671 & 29,178 \\
\hline Jimmy Jazz Records & $\begin{array}{l}\text { Punk rock } \\
\text { (independent } \\
\text { record label) }\end{array}$ & 4,546 & 5,095 & 1,068 & 1,602 \\
\hline
\end{tabular}

Source. Authors' compilation. 
leaders of the community. This does not mean that, in the case of other music genres, social networks do not exist, but rather that position of record labels in such networks is not as strong as in the case of hip-hop labels analyzed here.

It is worth addressing one more reason why hip-hop labels are so engaged in social media (especially on Facebook and YouTube). For several years now, we have observed increasingly frequent attempts in the hip-hop community to break the taboo associated with speaking in public about earning money from making music. Even in the 1990s, the view that music possessed a value in and of itself ("art for art's sake") dominated the hip-hop community; as such, making music for money was seen as a betrayal of the professional and community ethos. Nowadays, the situation has radically changed. As Kukołowicz and Jaczyński argue, "rappers, both American and Polish, are eager to praise their commercial success, which is considered in the hip-hop community as one of the characteristic features of being an outstanding artist." ${ }^{47}$ Respondents representing hip-hop labels also spoke openly about the profits coming from their recording activities. Therefore, social media, on one hand, has helped them to achieve commercial success (provide insight into fans' expectations, help predict future trends, etc.), while, on the other hand, it has created a natural space for them to communicate about those successes to the public.

\section{Conclusion}

Our respondents' answers suggest that, in terms of market analysis, the vast majority of record companies in Poland prefer using traditional approaches such as analysis of artists' creative potential and sales figures or observing artists' interaction with fans during live performances. Certainly for a long time, the internet has been used-even by the most conservative record companies dealing with classical music - to promote music and sell tangible records via a record company's website (mail order). In the majority of cases, however, maintaining an online presence has not included the actual analysis of the data acquired on the internet. Most of the analyzed labels either have not used any online market research methods or have limited research to the simple evaluation of their products' sales figures. At the same time, however, a group of hip-hop labels have pioneered new methods of gathering information on the internet. Such practices raise questions about the reasons for these labels' divergence from industry standards.

In conclusion, we would like to propose the thesis that the better a record label functions in social networks, the more useful information it has at its disposal for making release decisions (even if it decides not to buy data from external research companies). Social networks should be widely understood not just as networks that function on social networking sites but also as networks that connect people who participate in musical circles outside of the internet. To understand listeners' preferences, a music company must be embedded in social networks independently of how much they use the internet in their activities. In other words, for a record company that is entering the market "from nowhere" (i.e., it is a new player that is not embedded in social networks), it might be difficult to understand the musical tastes of its consumers and to reply with an offer that would evoke their interest. This is why independent record labels have been successful in discovering new sounds for many years; it also explains the successes of Polish hip-hop record companies. The difference between the 1980s and 1990s and present times pertains to the reliance of new media technologies, as well as the access to and analysis of data obtained from the internet. 
Following this line of thought, we would like to suggest that the approach of a given record label toward market research becomes a factor that enables the differentiation between the major/mainstream and independent record labels. In the past, controlling their own distribution network and striving to develop a "democratic" alternative to the capitalist methods of organizing music production was a criterion for differentiating "independent record labels" from other record labels (primarily, major record companies). ${ }^{48}$ For some time now, there has been a discussion about how "independence" in music should be understood. ${ }^{49}$ We would like to suggest that, as a part of redefining independence, the way that a given record label approaches broadly understood market research should be observed.

Labels representing the first of the approaches described above, especially major record companies, are market oriented. Therefore, it can be assumed that sooner or later they will implement any innovations that reduce their uncertainty about consumers' preferences. Such an approach carries with it all of the threats described by critical scholars: the surveillance of listeners and the progressive commodification of relations between artists and audiences.

Labels representing the second approach are well embedded in social networks, a condition that brings them valuable knowledge about consumers' preferences without having to buy access to data from external sources. Of course, we can assume that such labels will want to support release decisions with data purchased from external companies (such as Echo Nest) in the case of big or particularly risky (in the opinion of the record label) projects. The more often the company does this, the closer it gets to the first category of companies mentioned above. Such a balance "on a sliding scale between dependence and independence, freedom and control, nonprofit and free market ... often invoking hybrid arrangements" has been one of characteristic features of independent media for a long time. ${ }^{50}$ Perhaps in the future, labels who want to retain the independent status will be required to show that they try not to spy on their listeners.

The behavior of labels representing the third approach is difficult to predict based on our empirical material. This group is certainly not uniform - some labels represent conservative attitudes and will avoid analyzing online data, while in the future, others may implement elements of the other approaches. At least some of these labels are well embedded in social networks, yet these networks are not present on the internet and their analysis cannot be conducted online.

The classification proposed above may serve as the starting point for further research. We are of the opinion that using the concept of social network markets in the analysis of the functioning of record labels may bring valuable conclusions, especially considering that more and more of the actions of record labels are aimed not at traditional media, but at social media, thereby making their analysis easier for researchers.

\section{Appendix}

List of Labels Interviewed

4EVER MUSIC

Aloha Entertainment 
Ars Mundi

Bearton

Bocian Records

Bołt Records

CD Accord

DUX

ForTune

Green Star Music

Instant Classic

Jimmy Jazz Records

Karrot Kommando

KAYAX

Lado ABC

Latarnia Records"

Luna Music

Mathka

MaxFloRec

Mik Music!

MJM

Monotype Records

MTJ

Musica Sacra

Musicon

Muzyka Odnaleziona

My Music

Nasiono Records

NIFC

Paris Music

POLMIC

Polskie Nagrania

Preserved Sound 
Prosto

Radio Katowice

RAF

Rockers Publishing

Si Music

Silverton

Soliton

Sony Music Polska

STX Records

SUN MUSIC Records

Szpadyzor Records

U Know Me Records

Universal Music Polska

Victor11

Warner/Parlophone Music Poland [formerly EMI]

Wielkie Joł

Zoharum Records

${ }^{1}$ Patryk Galuszka is an assistant professor at the Faculty of Economics and Sociology at the University of Lodz. He has published articles in journals such as Media, Culture E Society, International Journal of Cultural Studies, Popular Music and Society, and International Journal of Communication. His research interests include creative industries, crowdfunding, popular music studies, and media economics. Katarzyna M. Wyrzykowska holds PhD degree in sociology. She is a researcher at the Institute of Philosophy and Sociology of Polish Academy of Sciences, a member of the Research Committee of Polish Music Council, Chair of Warsaw Department of Polish Sociological Association, and Secretary of Sociology of Arts Section of Polish Sociological Association. Her research interests focus on sociology of music, music market research, and the methodology of qualitative research. This work was supported by the Institute of Music and Dance, Polish Music Information Centre, and Ministry of Culture and National Heritage of the Republic of Poland.

${ }^{2}$ Paul M. Hirsch, "Processing Fads and Fashions: An Organization-Set Analysis of Cultural Industry Systems," American Journal of Sociology 77 (1972): 652-54.

${ }^{3}$ Richard E. Caves, Creative Industries: Contracts between Art and Commerce (Cambridge, MA: Harvard University Press, 2000), 3.

${ }^{4}$ ZPAV Polish Society of the Phonographic Industry, "Wzrost sprzedaży muzyki w Polsce i na świecie!" [Growing Music Sales in Poland and Around the World], (accessed April 30, 2017). 
${ }^{5}$ Jason Potts, Stuart Cunningham, John Hartley, and Paul Ormerod, "Social Network Markets: A New Definition of the Creative Industries," Journal of Cultural Economics 32 (2008): 167-85.

${ }^{6}$ Ibid.

${ }^{7}$ Bernard Miege, "The Cultural Commodity," Media, Culture \& Society 1 (1979): 300.

${ }^{8}$ Will Straw, "Music as Commodity and Material Culture," Repercussions 7 (1999): 156. It is worth noting here that this applies only to tangible releases.

${ }^{9}$ Steve Greenfield and Guy Osborn, "Understanding Commercial Music Contracts: The Place of Contractual Theory," Journal of Contract Law 23 (2007): 248-51. Andrew Leyshon, Peter Webb, Shaun French, Nigel Thrift, and Louise Crewe, "On the Reproduction of the Musical Economy after the Internet," Media, Culture \& Society 27 (2005): 187.

${ }^{10}$ Mark Lorenzen and Lars Frederiksen, "The Management of Projects and Product Experimentation: Examples from the Music Industry," European Management Review 2 (2005): 207.

${ }^{11}$ Simon Frith, "The A\&R Men," in The Beat Goes on: The Rock File Reader, ed. Charlie Gillett and Simon Frith (London: Pluto Press, 1996), 96.

${ }^{12}$ Koos Zwaan and Tom F. M. ter Bogt, "Breaking into the Popular Record Industry: An Insider's View on the Career Entry of Pop Musicians," European Journal of Communication 24 (2009): 97.

${ }^{13}$ Ibid.

${ }^{14}$ Keith Negus, "Recordings, Rights and Risks: Intermediaries and the Changing Music Industries," Civilisations: Revue Internationale D'Anthropologie et de Sciences Humaines 13 (2014): 125.

${ }^{15}$ Jeremy W. Morris, "Curation by Code: Infomediaries and the Data Mining of Taste," European Journal of Cultural Studies 18 (2015): 452.

${ }^{16}$ It should be noted, however, that similar (albeit not so broad) kinds of data were collected before the advent of the internet by such companies as Nielsen SoundScan. We would like to thank anonymous reviewer for calling our attention to this.

${ }^{17}$ Morris, "Curation by Code," 453.

${ }^{18}$ Potts et al., "Social Network Markets," 167-85.

${ }^{19}$ Ibid., 169.

${ }^{20}$ Nancy Baym, "The Swedish Model: Balancing Markets and Gifts in the Music Industry," Popular Communication 9 (2011): 22-38; Nancy Baym, "Fans or Friends? Seeing Social Media Audiences as Musicians Do," Participations 9 (2012): 286-316; David Beer, "Making Friends with Jarvis Cocker: Music Culture in the Context of Web 2.0.," Cultural Sociology 2 (2008): 222-41.

${ }^{21}$ John Banks and Jason Potts, "Co-creating Games: A Co-evolutionary Analysis," New Media \& Society 12 (2009): 253-70.

${ }^{22}$ Potts et al., "Social Network Markets," 171.

${ }^{23}$ Ibid.

${ }^{24}$ Elizabeth F. Churchill and Christine A. Halverson, "Guest Editors' Introduction: Social Networks and Social Networking," IEEE Internet Computing 9 (2005): 14.

${ }^{25}$ Potts et al., "Social Network Markets," 182.

${ }^{26}$ Pierre Bourdieu, Distinction: A Social Critique of the Judgement of Taste (London: Routledge, 1984). Edward L. Fink, John P. Robinson, and Sue Dowden, "Structure of Music Preference and Attendance," Communication Research 12 (1985): 301-18. Will 
Atkinson, "The Context and Genesis of Musical Tastes: Omnivorousness Debunked, Bourdieu Buttressed," Poetics 39 (2011): 169-86.

${ }^{27}$ Patryk Galuszka, “New Economy of Fandom," Popular Music and Society 38 (2015): 25-43.

${ }^{28}$ David Hesmondhalgh and Leslie M. Meier, "Popular Music, Independence and the Concept of the Alternative in Contemporary Capitalism," in Media Independence: Working with Freedom or Working for Free?, ed. James Bennett and Niki Strange (New York: Routledge, 2015): 94-116.

${ }^{29}$ Potts et al., "Social Network Markets", 167-85.

${ }^{30}$ See: Morris, "Curation by Code." Jeremy W. Morris, "Anti-market Research: Piracy, New Media Metrics, and Commodity Communities," Popular Communication 13 (2015): 446-63.

${ }^{31}$ Patrick Burkart and Tom McCourt, Digital Music Wars (Lanham, MD: Rowman \& Littlefield, 2006).

${ }^{32}$ Mark Andrejevic, "The Work of Being Watched: Interactive Media and the Exploitation of Self-Disclosure," Critical Studies in Media Communication 19, no. 2 (2002): 235.

${ }^{33}$ Ibid., 237.

${ }^{34}$ Mark Andrejevic, "Exploitation in the Data Mine," in Internet and Surveillance: The Challenges of Web 2.0 and Social Media, ed. Christian Fuchs, Kees Boersma, Anders Albrechtslund, and Marisol Sandoval (New York: Routledge, 2012), 86.

${ }^{35}$ Ben Sisario, "The Sweet, Streaming Sound of Data," New York Times, March 5, 2014, http:/ / www.nytimes.com/2014/03/07/business/media/the-sweet-streamingsound-of-data.html?_r=0 (accessed May 26, 2016).

${ }^{36}$ Adam Sherwin, "Thom Yorke Spotify Criticism: Top Producer Accuses Radiohead Singer of Twitter Hypocrisy," The Independent, July 15, 2013, http://www. independent.co.uk/arts-entertainment/music/news/thom-yorke-spotifycriticism-top-producer-accuses-radiohead-singer-of-twitter-hypocrisy-8709829. html (accessed April 30, 2017).

37 The International Federation of the Phonographic Industry, Recording Industry in Numbers: The Recorded Music Market in 2014 (London: The International Federation of the Phonographic Industry, 2015), 81.

${ }^{38}$ ZPAV Polish Society of the Phonographic Industry, "Polski rynek fonograficzny wzrósł o ponad 20\%" [Polish Recording Market Increases by More than 20\%], http:/ / zpav.pl/aktualnosc.php?idaktualnosci=1422 (accessed January 5, 2017).

${ }^{39}$ Ibid.

${ }^{40}$ See: Stephen Lee, "Re-examining the Concept of the 'Independent' Record Company: The Case of Wax Trax! Records," Popular Music 14 (1995): 13-31; Jon Stratton, "What Is 'Popular Music?'," The Sociological Review 31 (1983): 293-309. Frith, “The A\&R Men." Caves, Creative Industries. Zwaan and ter Bogt, "Breaking into the Popular Record Industry."

41 Zwaan and ter Bogt, "Breaking into the Popular Record Industry," 89-101.

${ }^{42}$ Potts et al., "Social Network Markets," 172.

${ }^{43}$ Morris, "Curation by Code.", 446-63.

${ }^{44}$ See: Philip Stade, "This Video Is Not Available in Germany: Online Discourses on the German Collecting Society GEMA and YouTube," First Monday 19 (2014), 
http:/ / firstmonday.org/ojs/index.php/fm/article/view/5548/4127 (accessed April 30, 2017).

${ }^{45}$ Mark Andrejevic, "Surveillance in the Digital Enclosure," The Communication Review 10 (2007): 295-317.

${ }^{46}$ Greg Dimitriadis, Performing Identity/Performing Culture: Hip Hop as Text, Pedagogy, and Lived Practice (New York: Peter Lang, 2009).

47 Tomasz Kukołowicz and Kamil Jaczyński, “Dumni Z pieniędzy. Artysta jako przedsiębiorca w (sub)kulturze hiphopowej" [Proud of Their Money. The Artist as an Entrepreneur in the Hip Hop (Sub)culture], Zarzadzanie w Kulturze 16 (2015): 65.

${ }^{48}$ David Hesmondhalgh, "Post-punk's Attempt to Democratise the Music Industry: The Success and Failure of Rough Trade," Popular Music 16 (1997): 255-74.

${ }^{49}$ Hesmondhalgh and Meier, "Popular Music, Independence and the Concept," 94-116.

${ }^{50}$ James Bennett, "Introduction: The Utopia of Independent Media: Independence, Working with Freedom and Working for Free," in Independence: Working with Freedom or Working for Free?, ed. James Bennett and Niki Strange (New York: Routledge, 2014), 11.

\section{Bibliography}

Andrejevic, Mark. "The Work of Being Watched: Interactive Media and the Exploitation of Self-Disclosure." Critical Studies in Media Communication 19, no. 2 (2002): 230-48.

Andrejevic, Mark. "Surveillance in the Digital Enclosure." The Communication Review 10 (2007): 295-317.

Andrejevic, Mark. “Exploitation in the Data Mine." In Internet and Surveillance: The Challenges of Web 2.0 and Social Media, edited by Christian Fuchs, Kees Boersma, Anders Albrechtslund, and Marisol Sandoval,71-88. New York: Routledge, 2012.

Atkinson, Will. "The Context and Genesis of Musical Tastes: Omnivorousness Debunked, Bourdieu Buttressed." Poetics 39 (2011): 169-86.

Banks, John, and Jason Potts. "Co-creating Games: A Co-evolutionary Analysis." New Media $\mathcal{E}$ Society 12 (2009): 253-70.

Baym, Nancy. "The Swedish Model: Balancing Markets and Gifts in the Music Industry." Popular Communication 9 (2011): 22-38.

Baym, Nancy. "Fans or Friends? Seeing Social Media Audiences as Musicians Do." Participations 9 (2012): 286-316.

Beer, David. "Making Friends with Jarvis Cocker: Music Culture in the Context of Web 2.0." Cultural Sociology 2 (2008): 222-41.

Bennett, James. "Introduction: The Utopia of Independent Media: Independence, Working with Freedom and Working for Free." In Independence: Working with Freedom or Working for Free?, edited by Bennett James and Strange Niki, 1-28. New York: Routledge, 2014.

Bourdieu, Pierre. Distinction: A Social Critique of the Judgement of Taste. London: Routledge, 1984.

Burkart, Patrick, and Tom McCourt. Digital Music Wars. Lanham, MD: Rowman \& Littlefield, 2006.

Caves, Richard E. Creative Industries: Contracts between Art and Commerce. Cambridge, MA: Harvard University Press, 2000. 
Churchill, Elizabeth F., and Christine A. Halverson. "Guest Editors' Introduction: Social Networks and Social Networking." IEEE Internet Computing 9 (2005): 14-19.

Dimitriadis, Greg. Performing Identity/Performing Culture: Hip Hop as Text, Pedagogy, and Lived Practice. New York: Peter Lang, 2009.

Fink, Edward L., John P. Robinson, and Dowden Sue. "Structure of Music Preference and Attendance." Communication Research 12 (1985): 301-18.

Frith, Simon. "The A\&R Men." In The Beat Goes on: The Rock File Reader, edited by Charlie Gillett and Simon Frith, 93-108. London: Pluto Press, 1996.

Galuszka, Patryk. "New Economy of Fandom," Popular Music and Society 38 (2015): 25-43.

Greenfield, Steve, and Guy Osborn. "Understanding Commercial Music Contracts: The Place of Contractual Theory," Journal of Contract Law 23 (2007): 248-68.

Hesmondhalgh, David. "Post-punk's Attempt to Democratise the Music Industry: The Success and Failure of Rough Trade." Popular Music 16 (1997): 255-74.

Hesmondhalgh, David and Leslie M. Meier. "Popular Music, Independence and the Concept of the Alternative in Contemporary Capitalism." In Independence: Working with Freedom or Working for Free?, edited by Bennett James and Strange Niki, 94-116. New York: Routledge, 2014.

Hirsch, Paul M. "Processing Fads and Fashions: An Organization-Set Analysis of Cultural Industry Systems." American Journal of Sociology 77 (1972): 639-59.

The International Federation of the Phonographic Industry. Recording Industry in Numbers: The Recorded Music Market in 2014. London: The International Federation of the Phonographic Industry, 2015.

Kukolowicz, Tomasz and Kamil Jaczyński. “Dumni Z pieniędzy. Artysta jako przedsiębiorca w (sub)kulturze hiphopowej" [Proud of Their Money. The Artist as an Entrepreneur in the Hip Hop (Sub)culture], Zarzadzanie w Kulturze 16 (2015): 61-79.

Lee, Stephen. "Re-examining the Concept of the 'Independent' Record Company: The Case of Wax Trax! Records." Popular Music 14 (1995): 13-31.

Leyshon, Andrew, Peter Webb, Shaun French, Nigel Thrift, and Louise Crewe. "On the Reproduction of the Musical Economy after the Internet." Media, Culture $\mathcal{E}$ Society 27 (2005): 177-209.

Lorenzen, Mark, and Lars Frederiksen. "The Management of Projects and Product Experimentation: Examples from the Music Industry." European Management Review 2 (2005): 198-211.

Miege, Bernard. “The Cultural Commodity.” Media, Culture E Society 1 (1979): 297-311.

Morris, Jeremy W. "Anti-market Research: Piracy, New Media Metrics, and Commodity Communities." Popular Communication 13 (2015): 32-44.

Morris, Jeremy W. “Curation by Code: Infomediaries and the Data Mining of Taste." European Journal of Cultural Studies 18 (2015): 446-63.

Negus, Keith. "Recordings, Rights and Risks: Intermediaries and the Changing Music Industries." Civilisations: Revue Internationale D'Anthropologie et de Sciences Humaines 13 (2014): 113-36.

Potts, Jason, Stuart Cunningham, John Hartley, and Paul Ormerod. "Social Network Markets: A New Definition of the Creative Industries." Journal of Cultural Economics 32 (2008): 167-85.

Sherwin, Adam. "Thom Yorke Spotify Criticism: Top Producer Accuses Radiohead Singer of Twitter Hypocrisy." The Independent, July 15, 2013. http:/ / www.independent.co.uk/ arts-entertainment/music/news/thom-yorke-spotify-criticism-top-producer-accusesradiohead-singer-of-twitter-hypocrisy-8709829.html (accessed April 30, 2017). 
Sisario, Ben. “The Sweet, Streaming Sound of Data." New York Times, March 5, 2014. http:// www.nytimes.com/2014/03/07/business/media/the-sweet-streaming-sound-of-data. html?_r=0 (accessed May 26, 2016).

Stade, Philip. "'This Video Is Not Available in Germany': Online Discourses on the German Collecting Society GEMA and YouTube." First Monday 19 (2014). http:/ / firstmonday. org/ojs/index.php/fm/article/view/5548/4127 (accessed April 30, 2017).

Stratton, Jon. “What Is 'Popular Music'?." The Sociological Review 31 (1983): 293-309.

Straw, Will. "Music as Commodity and Material Culture." Repercussions 7 (1999): 147-71.

ZPAV Polish Society of the Phonographic Industry. "Polski rynek fonograficzny wzrósł o ponad 20\%" [Polish Recording Market Increases by More than 20\%]. http://zpav.pl/ aktualnosc.php?idaktualnosci=1422 (accessed January 5, 2017).

ZPAV Polish Society of the Phonographic Industry, "Wzrost sprzedaży muzyki w Polsce i na świecie!" [Growing Music Sales in Poland and Around the World] (accessed April 30, 2017).

Zwaan, Koos, and Tom F. M. ter Bogt. "Breaking into the Popular Record Industry: An Insider's View on the Career Entry of Pop Musicians." European Journal of Communication 24 (2009): 89-101. 